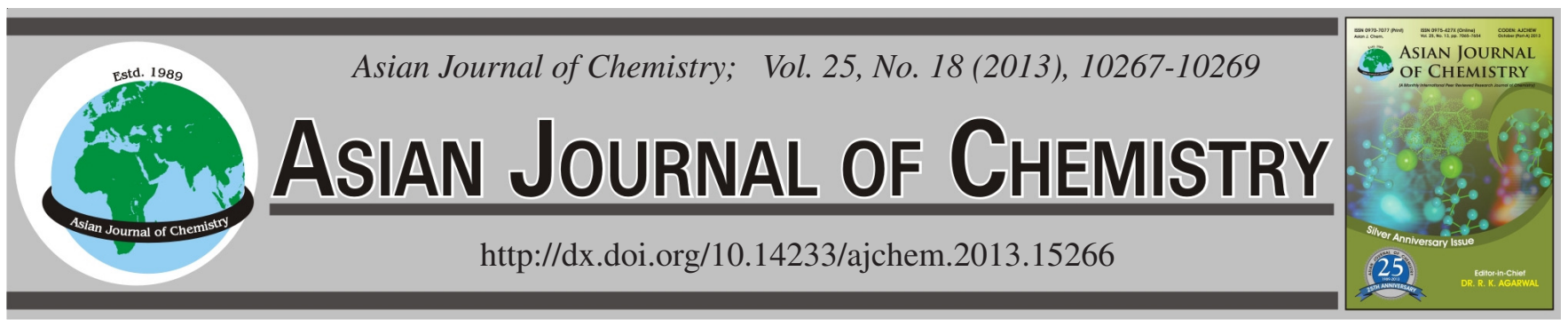

\title{
Determination of Sarafloxacin in Eggs by Flow Injection Chemiluminescence Combined with Solid-Phase Extraction
}

\author{
Yue-Ying LiU and Shi-Hao Zhao*
}

College of Biology Science and Engineering, Hebei University of Economics and Business, Shijiazhuang 050061, P.R. China

*Corresponding author: Tel: +86 311 87656833; E-mail: zhaoshihao_1@163.com

A simple flow injection chemiluminescence method was developed for the rapid and sensitive determination of sarafloxacin in animal eggs. The study based on the chemiluminescence induced by $\mathrm{H}_{2} \mathrm{O}_{2}$ and luminol in $\mathrm{NaOH}$ medium, sarafloxacin could dramatically enhance chemiluminescence intensities and incorporated with solid-phase extraction. The chemiluminescence system has been applied for the determination of sarafloxacin in eggs. Under optimum conditions, the chemiluminescence intensities were linearly related to the concentration of sarafloxacin in the range of $2.0 \times 10^{-7}$ to $8.0 \times 10^{-5} \mathrm{~g} \mathrm{~L}^{-1}$ with a correlation coefficient of 0.9992 and the detection limit was $4.0 \times 10^{-8} \mathrm{~g} \mathrm{~L}^{-1}$. The relative standard deviation was $2.4 \%$ for $5.0 \times 10^{-6} \mathrm{~g} \mathrm{~L}^{-1}$ sarafloxacin.

Key Words: Sarafloxacin, Flow injection, Chemiluminescence, Luminol, $\mathrm{H}_{2} \mathrm{O}_{2}$.

\section{INTRODUCTION}

Sarafloxacin (SAR) is a broad spectrum antibacterial chemical agent of fluoroquinolone family that has been recommended for the treatment of bacterial diseases in animal husbandry and aquaculture. It has been used in veterinary applications owing to enhancing antibacterial activities against gram-positive and gram-negative organisms ${ }^{1-4}$. Quinolones and antibiotics, in general, are both used for prophylaxis and the treatment of diseases and as feed additives for mass gain promotion $^{5,6}$. A significant and progressive increase in the use of sarafloxacin in animal production was noted in the recent years. There are concerns that the widespread usage of antibiotics may be responsible for the promotion of resistant stains of bacteria ${ }^{7,8}$. There is now a strict legislative framework controlling the use of these substances, with the aim of minimising the risk to human health associated with consumption of their residues. Therefore, to ensure human food safety, a recommended dose rate of $10 \mathrm{mg} / \mathrm{kg}$ body weight/day, administered in the feed as sarafloxacin hydrochloride for 5 consecutive days. It has been approved in the European Union by the Regulation No. 1568/98 for salmonidae with a maximum residue limit (MRL) of $30 \mu \mathrm{g} / \mathrm{kg}$ in the target tissue of muscle plus skin in natural proportions.

Therefore, it is important to develop simple, sensitive and accurate methods for being able to detect sarafloxacin. Methods of analysis for sarafloxacin are grouped into Enzyme-Linked Immunosorbent Assay (ELIA $)^{9}$, capillary electrophoresis $(\mathrm{CE})^{10}$, high-performance liquid chromatography (HPLC) ${ }^{11}$. Although enzyme-linked immunosorbent assay is the most commonly used method, it is time consuming, needs great care and skill. CE and HPLC methods have the advantage of separating and quantifying different forms of sarafloxacin and its derivations and minimum interference from enzymes but involve set up cost, a complex extraction and purification procedure. Chemiluminescence $(\mathrm{CL})$ is an attractive detection method because of the low detection limit, rapidity, wide linear working range and simple instrumentation ${ }^{12-14}$.

In this study, we found that a strong chemiluminescence signal was given out when a trace amount of sarafloxacin was added to luminol- $\mathrm{H}_{2} \mathrm{O}_{2}$ mixed solution and the chemiluminescence intensity was strongly dependent on sarafloxacin concentration. Based on this phenomenon, a rapid, sensitive and inexpensive chemiluminescence method with solid-phase extraction (SPE) technique was proposed to determine sarafloxacin. The effect of reaction conditions on the chemiluminescence signal intensity was explored in the flow injection (FI) mode of analysis. Under the optimized conditions, the proposed FI-CL-SPE system was applied for the determination of sarafloxacin in eggs.

\section{EXPERIMENTAL}

Sarafloxacin was obtained from China Institute of Veterinary Drugs Control (Beijing, China). A stock solution (0.2 g $\mathrm{L}^{-1}$ ) was prepared by dissolving $20.0 \mathrm{mg}$ sarafloxacin in $2 \mathrm{~mL}$ of $0.1 \mathrm{M} \mathrm{NaOH}$ solution and diluting to $100 \mathrm{~mL}$ with water. 
Luminol was obtained from Sigma-Aldrich (St. Louis, Mo, USA). A stock solution $\left(0.01 \mathrm{~mol} \mathrm{~L}^{-1}\right)$ of luminol was prepared by dissolving $0.443 \mathrm{~g}$ luminol in $5 \mathrm{~mL}$ of $1 \mathrm{~mol} \mathrm{~L}^{-1} \mathrm{NaOH}$ and then transferring the solution into a $250 \mathrm{~mL}$ volumetric flask and diluting with water. The solutions were stored at $4{ }^{\circ} \mathrm{C}$ and diluted to working solutions with water. The BPS buffer solution ( $\mathrm{pH}=7.0$ ) was prepared by dissolving $0.78 \mathrm{~g} \mathrm{NaH}_{2} \mathrm{PO}_{4}$ and $29.1 \mathrm{~mL} 0.1 \mathrm{M} \mathrm{NaOH}$ and diluting to $100 \mathrm{~mL}$ with water. $\mathrm{NaOH}, \mathrm{NaHCO}_{3}, \mathrm{Na}_{2} \mathrm{CO}_{3}, \mathrm{Na}_{2} \mathrm{HPO}_{4}, \mathrm{NaH}_{2} \mathrm{PO}_{4}, \mathrm{H}_{2} \mathrm{O}_{2}, n$-hexane and methanol were obtained either from Beijing Chemical Reagent Company (Beijing) or from Tianjin Chemical Reagent Company (Tianjin, China). All the above reagents were of analytical grade and used as received without further purification. Double-distilled water (referred to pure water thereafter) was used as carrier flow and for the preparation of solutions. The diluted working solutions were prepared and used freshly and daily.

Flow injection-chemiluminescence was performed with an IFFL-D flow injection chemiluminescence analysis system (Xi' an Ruike Electronic equipment Corporate, Xi'an, China). The schematic diagram of the FI-CL analyzer is shown in Fig. 1. It consisted of 2 peristaltic pumps (working at a constant flow rate of $30 \mathrm{rpm}$ ). One channel was used to carry $\mathrm{NaOH}$ and luminol solution, the other channel was used to carry the $\mathrm{H}_{2} \mathrm{O}_{2}$ solution, Sample solutions were then injected from a sample valve. The enhanced chemiluminescence signals were produced immediately and were recorded. The flow cell was a $10 \mathrm{~cm}$ long spiral glass tubing ( $2.0 \mathrm{~mm}$ i.d.) and the distance between injection valve and flow cell was $15 \mathrm{~cm}$.

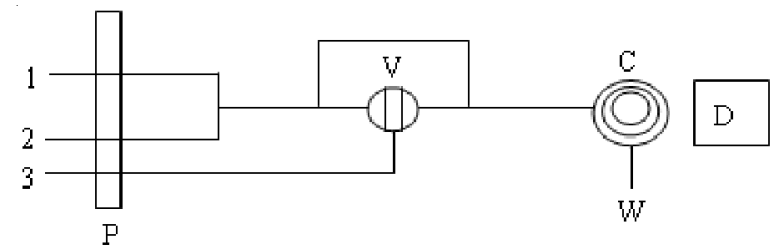

Fig. 1. Schematic diagram of flow injection chemiluminescence analysis. 1. Mixture of $\mathrm{NaOH}$ and luminol. 2. $\mathrm{H}_{2} \mathrm{O}_{2}$ solution. 3. Sarafloxacin solution. C. Flow cell. V. Injection valve. W. Waste solution. D. Detector

Sample preparation: $1 \mathrm{~g}$ of homogenate of egg was accurately weighted into a $50 \mathrm{~mL}$ polypropylene centrifuge tube, $3 \mathrm{~mL}$ BPS buffer solution was added and vortex-mixed, followed by centrifugation for $10 \mathrm{~min}$ at $5000 \mathrm{rpm}$, the residue was repeated one time. Then the upper layer were moved into a centrifuge tube, $3 \mathrm{~mL} n$-hexane was added and vortex-mixed for $5 \mathrm{~min}$, followed by centrifugation for $10 \mathrm{~min}$ at $5000 \mathrm{rpm}$, After standing for $5 \mathrm{~min}$, the upper layer was pipetted out and discarded.

The $n$-hexane defatting step was repeated by adding another $3 \mathrm{~mL}$ of hexane into the low layer. Then the low layer was purified by SPE.

Solid phase extraction of sample procedure: For SPE, sarafloxacin sample cartridges with Waters Sep-pak $\mathrm{C}_{18}$ vacuum (200 mg, $3 \mathrm{~mL}$ ) were used as clean-up and enrichment devices. $3 \mathrm{~mL}$ of sample was loaded onto SPE vacuum that had been preconditioned with $3 \mathrm{~mL}$ of methanol and equilibrated with $3 \mathrm{~mL}$ of distilled water. Sample was washed with
$1 \mathrm{~mL}$ of 3 water/methanol (90/10, v/v). Elution was achieved with $2.0 \mathrm{~mL}$ of methanol. The eluate was evaporated to dryness under a gentle stream of $\mathrm{N}_{2}$. Elutropic solutions were into a 50 $\mathrm{mL}$ volumetric flask and diluted with water for the flow injection chemiluminescence analysis.

\section{RESULTS AND DISCUSSION}

Optimization of experimental variables: The chemiluminescence emission that results from the reaction of luminol and $\mathrm{H}_{2} \mathrm{O}_{2}$ is not significant enough, which has relatively low sensitivity. When sarafloxacin was added in this system, the chemiluminescence emission increased. The significant increase indicated sarafloxacin was a sensitive enhancer on the chemiluminescence reaction of luminol- $\mathrm{H}_{2} \mathrm{O}_{2}$. Furthermore, the emission intensity was proportional to the concentration of sarafloxacin. The sensitizing effect of sarafloxacin on the chemiluminescence emission was also related to the alkalinity of solution and the concentrations of $\mathrm{H}_{2} \mathrm{O}_{2}$ and luminol. Thus, a series of experiments were performed to optimize the conditions for the production of maximum chemiluminescence emission.

The effect of acid contained in the solution on the chemiluminescence emission was initially examined. The chemiluminescence emission intensity of $5.0 \times 10^{-6} \mathrm{~g} \mathrm{~L}^{-1}$ sarafloxacin$6.0 \times 10^{-4} \mathrm{~mol} \mathrm{~L}^{-1}$ luminol-4.0 $\times 10^{-2} \mathrm{~mol} \mathrm{~L}^{-1} \mathrm{H}_{2} \mathrm{O}_{2}$ system in the presence of $\mathrm{NaOH}, \mathrm{NaHCO}_{3}, \mathrm{Na}_{2} \mathrm{CO}_{3}, \mathrm{Na}_{2} \mathrm{HPO}_{4}$ and $\mathrm{NaH}_{2} \mathrm{PO}_{4}$ at the same concentration was detected. The results indicated that the strongest chemiluminescence emission occurred in alkalinity medium containing $\mathrm{NaOH}$. With the increasing concentration of $\mathrm{NaOH}$, the chemiluminescence emission intensity increased and reached a maximum value at $2 \times 10^{-2} \mathrm{~mol} \mathrm{~L}^{-1}$. Therefore, $2 \times 10^{-2} \mathrm{~mol} \mathrm{~L}^{-1} \mathrm{NaOH}$ was chosen as the carrier flow.

The effect of $\mathrm{H}_{2} \mathrm{O}_{2}$ concentration on chemiluminescence intensity was examined in the range of $1.0 \times 10^{-2}$ to $7.0 \times$ $10^{-2} \mathrm{~mol} \mathrm{~L}^{-1}\left(2.0 \times 10^{-2} \mathrm{~mol} \mathrm{~L}^{-1} \mathrm{NaOH}, 5.0 \times 10^{-6} \mathrm{~g} \mathrm{~L}^{-1}\right.$ sarafloxacin and $6.0 \times 10^{-4} \mathrm{~mol} \mathrm{~L}^{-1}$ luminol). The chemiluminescence intensity increased with an increasing concentration of $\mathrm{H}_{2} \mathrm{O}_{2}$ and then reached a maximum value at the $\mathrm{H}_{2} \mathrm{O}_{2}$ concentration of $4.0 \times 10^{-2} \mathrm{~mol} \mathrm{~L}^{-1}$. Larger concentrations resulted in a decrease of the emission intensity (Fig. 2). Therefore $4.0 \times$ $10^{-2} \mathrm{~mol} \mathrm{~L}^{-1} \mathrm{H}_{2} \mathrm{O}_{2}$ was used for subsequent work.

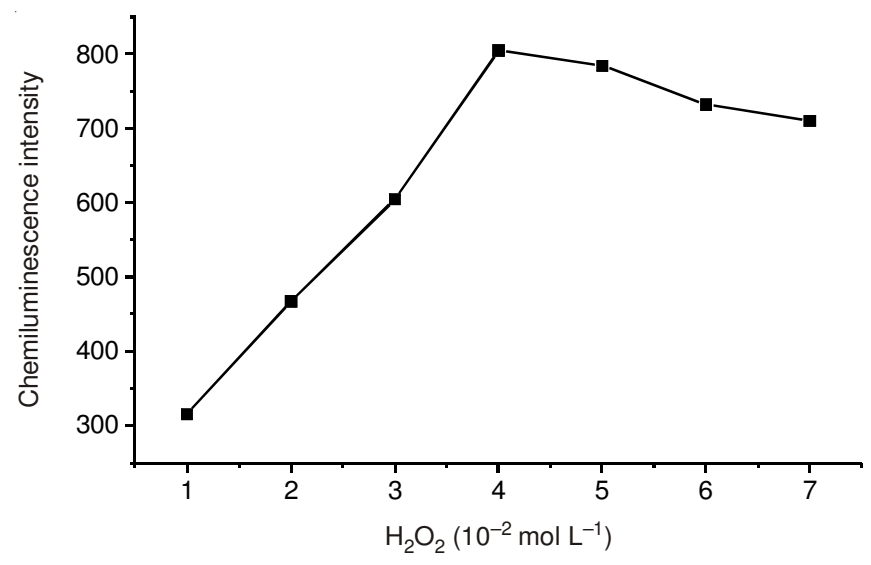

Fig. 2. Effect of $\mathrm{H}_{2} \mathrm{O}_{2}$ concentration on chemiluminescence intensity. Condition: $[\mathrm{SAR}]=5.0 \times 10^{-6} \mathrm{~g} \mathrm{~L}^{-1}$, [luminol] $=6.0 \times 10^{-4} \mathrm{~mol} \mathrm{~L}^{-1}$, luminol in $2.0 \times 10^{-2} \mathrm{~mol} \mathrm{~L}^{-1} \mathrm{NaOH}$ solution 
The effect of luminol concentration on the chemiluminescence intensity in the presence of $5.0 \times 10^{-6} \mathrm{~g} \mathrm{~L}^{-1}$ sarafloxacin and $4.0 \times 10^{-2} \mathrm{~mol} \mathrm{~L}^{-1} \mathrm{H}_{2} \mathrm{O}_{2}$ in $2.0 \times 10^{-2} \mathrm{~mol} \mathrm{~L}^{-1} \mathrm{NaOH}$ was studied. The result showed that the chemiluminescence intensity increased with the increase of the concentration of luminol when it was lower than $6.0 \times 10^{-4} \mathrm{~mol} \mathrm{~L}^{-1}$ (Fig. 3). Thus, $6.0 \times$ $10^{-4} \mathrm{~mol} \mathrm{~L}^{-1}$ luminol was chosen for the present work.

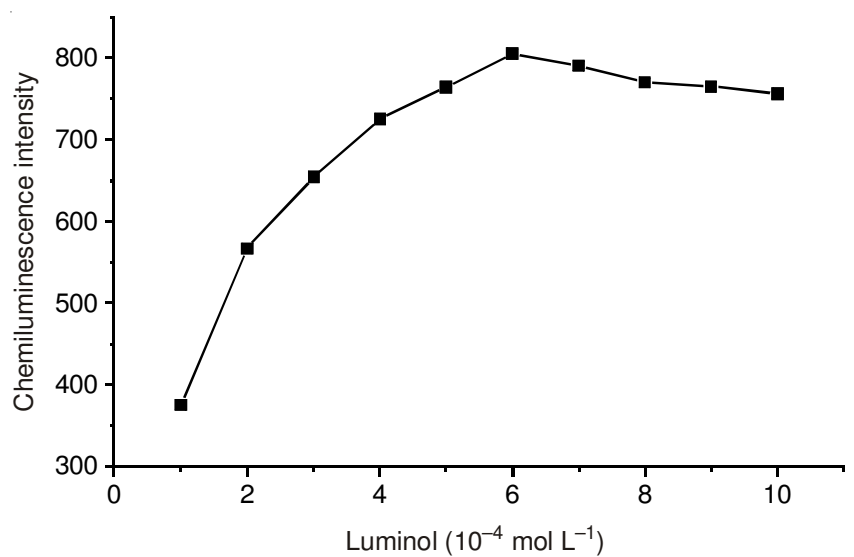

Fig. 3. Effect of luminol concentration on chemiluminescence intensity. Condition: $[\mathrm{SAR}]=5.0 \times 10^{-6} \mathrm{~g} \mathrm{~L}^{-1},\left[\mathrm{H}_{2} \mathrm{O}_{2}\right]=2.0 \times 10^{-2} \mathrm{~mol} \mathrm{~L}^{-1}$, luminol in $2.0 \times 10^{-2} \mathrm{~mol} \mathrm{~L}^{-1} \mathrm{NaOH}$ solution

Kinetic characteristics of the chemiluminescence reaction: The kinetic behaviour of the chemiluminescence reaction of sarafloxacin- $\mathrm{H}_{2} \mathrm{O}_{2}$-luminol was studied with a static method. The chemiluminescence reaction occurred immediately after mixing luminol with the solution containing $\mathrm{H}_{2} \mathrm{O}_{2}$ and sarafloxacin and reached a maximum within $2 \mathrm{~s}$. The chemiluminescence reaction could take $25 \mathrm{~s}$ for the signal to return to zero. Thus, the chemiluminescence reaction is very rapid emission.

Performance of the system for sarafloxacin measurements: Under the optimum conditions mentioned above, the calibration curve was obtained for determination of sarafloxacin by plotting the chemiluminescence signal versus sarafloxacin concentration, which gave a linear range from 2 $\times 10^{-7}$ to $8 \times 10^{-5} \mathrm{~g} \mathrm{~L}^{-1}$ with a correlation coefficient of 0.9997 . A regression equation was obtained as:

$$
\text { Intensity }=201.52+130.23 \mathrm{c}\left(\mathrm{c}: 10^{-6} \mathrm{~g} \mathrm{~L}^{-1}\right)
$$

The detection limit was $4.0 \times 10^{-8} \mathrm{~g} \mathrm{~L}^{-1}$, which was calculated as the amount of sarafloxacin required to yield a net peak three times the standard deviation of the background signal $(3 \sigma)$. The relative standard deviation for 11 repetitive determinations of $5 \times 10^{-6} \mathrm{~g} \mathrm{~L}^{-1}$ sarafloxacin was $2.4 \%$, showing a good reproducibility.

Study of interferences: In order to assess the possible analytical application of the proposed chemiluminescence system to samples, the influences of some common inorganic ions and a couple of relevant organic compounds on chemiluminescence intensities were investigated for measuring $5.0 \times$
$10^{-6} \mathrm{~g} \mathrm{~L}^{-1}$ sarafloxacin. The tolerable concentration ratios with respect to $5.0 \times 10^{-6} \mathrm{~g} \mathrm{~L}^{-1}$ sarafloxacin standard solution for interference at less than $5 \%$ level were over: 500 for $\mathrm{K}^{+}, \mathrm{Na}^{+}$, $\mathrm{Cl}^{-}, \mathrm{NH}_{4}^{+} ; 100$ for $\mathrm{Ca}^{2+}, \mathrm{Mg}^{2+}, \mathrm{Zn}^{2+}$, L-histidine acid; 50 for $\mathrm{Fe}^{3+}, \mathrm{Fe}^{2+}, \mathrm{I}^{-}$, glucose, fructose, respectively.

Sample analysis: The proposed method was applied to the determination of sarafloxacin in eggs. The recovery experiment of adding standard had been done at the same time. the relevant data were displayed in Table-1. The recoveries were in the range of 89.6-105.4\% and the average recovery was $93.8 \%$.

TABLE-1

DETERMINATION RESULTS OF SARAFLOXACIN IN EGGS

\begin{tabular}{cccccc}
\hline Samples & $\begin{array}{c}\text { Found } \\
\left(\mu \mathrm{g} \mathrm{g}^{-1}\right)\end{array}$ & $\begin{array}{c}\text { Added } \\
\left(\mu \mathrm{g} \mathrm{g}^{-1}\right)\end{array}$ & $\begin{array}{c}\text { Total } \\
\text { found } \\
\left(\mu \mathrm{g} \mathrm{g}^{-1}\right)\end{array}$ & $\begin{array}{c}\text { Recovery } \\
(\%)\end{array}$ & $\begin{array}{c}\text { Average } \\
\text { recovery } \\
(\%)\end{array}$ \\
\hline 1 & - & & 0.0918 & 91.8 & \\
2 & - & & 0.0896 & 89.6 & \\
3 & 0.0724 & 0.1000 & 0.1778 & 105.4 & 93.8 \\
4 & 0.0866 & & 0.1790 & 92.4 & \\
5 & - & & 0.0932 & 93.2 & \\
6 & 0.1247 & & 0.2151 & 90.4 & \\
\hline
\end{tabular}

\section{Conclusion}

Sarafloxacin greatly enhance the chemiluminescence signal of luminol by reaction with $\mathrm{H}_{2} \mathrm{O}_{2}$ in alkalinity media. Based on this, a FL-CL with SPE method for the determination of sarafloxacin has been developed. The proposed method is sensitive, fast and simple and did not require sophisticated reagents and equipment. This method was used for the determination of sarafloxacin in eggs injection with satisfactory results.

\section{REFERENCES}

1. R.N. Jones and M.E. Erwin, Diagn. Microbiol. Infect. Dis., 32, 55 (1998).

2. N. Chansiripornchai and J. Sasipreeyajan, Vet. Res. Commun., 26, 255 (2002).

3. M.L. McConville, J.W. Dijkstra, J.M. Stamm, J.J. van Saene and J.F. Nouws, Vet. Quart., 17, 1 (1995).

4. V. Korten and B.E. Murray, Drugs, 45, 125 (1993).

5. L.K. Sørensen and L.K. Snor, J. Chromatogr. A, 882, 145 (2000).

6. E. Rodriguez, M.C. Moreno-Bondi and M.D. Marazuela, Food Chem., 127, 1354 (2011).

7. J.G. Salisbury, T.J. Nicholls, A.M. Lammerding, J. Turnidge and M.J. Nunn, Int. J. Antimicrob. Agents, 20, 153 (2002).

8. K. Chiba, A. Sugiyama, T. Hagiwara, S. Takahashi, K. Takasuna and K. Hashimoto, Eur. J. Pharmacol., 486, 189 (2004).

9. J.Q. Jiang, H.T. Zhang and Z.L. Wang, Procedia Environ. Sci., 8, 301 (2011).

10. D. Barrón, E. Jiménez-Lozano, S. Bailac and J. Barbosa, J. Chromatogr. $B, 767,313$ (2002).

11. W.H. Gingerich, J.R. Meinertz, V.K. Dawson, J.E. Gofus, L.J. Delaney and P.R. Bunnell, Aquaculture, 131, 23 (1995).

12. P. Rolewski, A. Siger, M. Nogala-Kalucka and K. Polewski, Food Res. Int., 42, 165 (2009).

13. S.H. Zhao, P.P. Zhang and S.B. Zhao, Asian J. Chem., 22, 7557 (2010).

14. S.H. Zhao, P.P. Zhang, X.H. Liang, D.L. Hua, T. Ma and G. Pei, J. Food Sci., 77, 102 (2012). 